\title{
DESEMPENHO OPERACIONAL DE CONJUNTO TRATOR-GRADE EM ARGISSOLO AMARELO NO SEMIÁRIDO NORDESTINO
}

\author{
PEQUENO, Izaac Damasceno ${ }^{1}$ \\ ARCOVERDE, Salvio Napoleão Soares ${ }^{1}$ \\ CORTEZ, Jorge Wilson ${ }^{2}$ \\ GARRIDO, Marlon da Silva ${ }^{2}$ \\ CARVALHO, Paulo Gustavo Serafim de ${ }^{2}$
}

RESUMO: A grade de discos é um implemento de preparo periódico do solo que, muitas vezes, não é utilizada de forma correta em solos do semiárido, sobretudo, pelo incipiente conhecimento sobre o seu comportamento. Assim, instalou-se no Centro de Ciências Agrárias da UNIVASF em Petrolina - PE, um experimento com o objetivo de se avaliar o desempenho operacional de um conjunto trator - grade no preparo periódico do solo, variando as marchas do trator e os ângulos de tração do implemento em um Argissolo Amarelo. Os parâmetros medidos foram: velocidade teórica e velocidade real de avanço, largura de corte, profundidade de trabalho, as capacidades de campo, e a estimativa de força de tração e potência na barra. Os dados foram analisados pela análise de variância e por meio de regressão polinomial quando significativo a pelo menos $5 \%$ de probabilidade no teste de F. Os resultados obtidos mostraram que os valores de largura de corte e a profundidade de trabalho decrescem com o aumento do ângulo de tração e velocidade de deslocamento do conjunto; o comportamento da velocidade de deslocamento mostrou-se inversamente proporcional ao ângulo de tração e diretamente a marcha do trator; as capacidades de campo teórica e efetiva, e a potência apresentaram dependência do fator marcha (velocidade), e a força de tração teve relação direta com o ângulo de tração e com a profundidade de trabalho.

Palavras-chave: Máquinas agrícolas. Capacidade de campo. Profundidade de trabalho.

\section{OPERATIONAL PERFORMANCE OF TRACTOR-HARROWS YELLOW ULTISOL IN THE SEMIARID NORTHEASTERN}

SUMMARY: The disc harrow is an implement of soil tillage, which often is not used correctly in the semi-arid soils, especially by the incipient knowledge about their behavior. Thus, it was installed at the Center for Agricultural Sciences UNIVASF Petrolina - PE, experiment with the objective of evaluating the operating performance of a tractor - grid in preparation of the soil, varying the speed of the tractor and the angles of traction implement in an Ultisol. The parameters measured were: theoretical speed and actual speed of advance, cutting width, working depth of field capacity, and estimated traction force and drawbar power. Data were analyzed by regression polynomial significant when at least $5 \%$ probability test $\mathrm{F}$. The results showed that the values width and depth of cutting work decreases with increasing angle of forward speed and tension set, the behavior of the forward speed was inversely proportional to the angle of traction and directly movement of the tractor; capabilities and effective field theory, and power factor are dependent on gear (speed) and tensile strength was directly related to the angle of pull and the working depth.

Keywords: Agricultural machinery. Field capacity. Working depth.

\section{INTRODUÇÃO}

O trabalho de produção agrícola é desenvolvido em etapas denominadas de operações agrícolas. Constituem-se em fases dependentes das condições climáticas do local, dos estágios de desenvolvimento e produção das culturas. Desta forma, as diversas operações de campo, realizadas com o auxílio de máquinas agrícolas, devem ser executadas de maneira racional, a fim de facilitar a utilização econômica

\footnotetext{
${ }^{1}$ Eng. Agrícola e Ambiental, Mestrando em Engenharia Agrícola na UNIVASF.

${ }^{2}$ Prof. Dr. da Universidade Federal do Vale do São Francisco
} 
das máquinas.

O gerenciamento da produção agrícola deve minimizar, entre outros fatores, o custo da maquinaria agrícola em relação ao custo total de produção. Nesse sentido, a seleção da maquinaria apresenta-se como um componente desse processo que, entre outros aspectos, deve atender as operações de forma a desenvolver o trabalho em um menor tempo possível.

Para Pacheco (2000) o propósito da seleção de máquinas agrícolas, neste caso relacionadas ao preparo do solo é, sobretudo, a realização dessas operações da forma mais racional possível, levando-se em conta a capacidade operacional e a eficiência de campo, com aumento de desempenho e máximo de economia na sua utilização.

Segundo Mantovani (1987), a exploração de grandes áreas requer alta capacidade efetiva de trabalho (ha. ${ }^{-1}$ ) dos equipamentos agrícolas com o uso intenso de alguns implementos, como a grade que, tem sido uma constante no preparo do solo e, neste cenário, a eficiência de trabalho aumenta em detrimento da qualidade do manejo do solo. Nesse aspecto, vários são os impactos causados à estrutura do solo devido a intensificação do uso de máquinas de preparo periódico, a exemplo das grades e outros equipamentos pesados, responsáveis pela desestruturação e alterações de suas propriedades físicas, evidenciadas pela compactação, colocando em risco a sustentabilidade de um sistema produtivo (SILVA et al., 1996) .

Em virtude do potencial agrícola da região do semiárido nordestino, no que diz respeito à fruticultura irrigada, faz-se necessário pesquisas para a obtenção de dados resultantes de trabalhos de campo de preparo periódico do solo, esses, na maioria das vezes, realizados sem nenhum critério técnico, de modo que permita contribuir com informações a agricultores e técnicos, relacionadas ao comportamento dos diversos implementos por eles utilizados, provenientes da interação solo-máquina (BIANCHINI et al., 1999).

Pressupõe-se que a velocidade de deslocamento do conjunto e a profundidade de penetração do equipamento em função dos ângulos de tração modificados em função da posição da barra de tração, aliados ao tipo de solo e condições de umidade, podem influenciar tanto no desempenho operacional como na força de tração e na potência requerida.

O objetivo do presente trabalho foi avaliar a influência das posições da barra de tração e dos respectivos ângulos, e a velocidade de deslocamento no desempenho operacional do conjunto trator-grade, em trabalho de preparo periódico do solo.

\section{MATERIAL E MÉTODOS}

\section{Caracterização da área experimental}

O presente estudo foi conduzido no Campus de Ciências Agrárias da Universidade Federal do Vale do São Francisco - UNIVASF em Petrolina - PE, que se localiza a latitude de $09^{\circ} 23^{\prime}$ sul, longitude de 40 $30^{\prime}$ oeste e altitude de $376 \mathrm{~m}$. Segundo a classificação de Köppen, o clima da região apresenta-se como tropical semiárido, tipo BshW, caracterizado pela escassez e irregularidade das precipitações com chuvas no verão e forte evaporação em conseqüência das altas temperaturas.

O solo foi classificado como Argissolo Amarelo (EMBRAPA, 2006) que apresenta na camada de 0-20 $\mathrm{cm}$ de profundidade $85,9 \%$ de areia, $8,5 \%$ de silte e 5,6\% de argila.O solo, durante os ensaios, encontrava-se com umidade de $9,8 \%$ na camada $0,00-0,20 \mathrm{~m}$ de profundidade e a umidade obtida para a capacidade de campo do solo foi de $17,7 \%$.

A área do experimento foi previamente roçada e apresentava cobertura vegetal rasteira, constituída basicamente de pequenas erva e gramíneas infestantes.

Nucleus, v.9, n.2, out.2012 


\section{Delineamento estatístico, equipamento e coleta de dados}

O delineamento experimental adotado foi em blocos casualizados, com parcelas subdividas, sendo cada parcela útil de $80 \mathrm{~m}$ de comprimento e $2,5 \mathrm{~m}$ de largura. A análise dos dados seguiu o esquema fatorial (4 x 3), sendo quatro posições da barra de tração da grade $(1,2,3$ e 4) e as machas de deslocamento do conjunto trator-grade (L3, H1 e H2), com 4 repetições, perfazendo um total de 48 parcelas experimentais.

Como fonte de potência foi utilizado trator da marca: Valtra, modelo: 785 TDA (tração dianteira auxiliar), com $75 \mathrm{cv}(55,2 \mathrm{~kW})$, motor fabricado em 2004 com 3.100 horas de uso, com pneus dianteiros 12.4-24 R1 e traseiros 18.4-30 R1, e rotação de trabalho no motor a $2.040 \mathrm{rpm}$.

O implemento utilizado foi uma grade leve do tipo off-set, Marchesan TATU, modelo: GAM, fabricada em 1994, com 8 discos em cada seção (duas), sendo recortados de 22" (0,558 m) e distância entre discos de 0,23 $\mathrm{m}$. Profundidade média de trabalho de $0,15 \mathrm{~m}$ determinada no momento de preparo com auxilio de uma trena graduada em cinco locais.

Para determinação da velocidade de deslocamento na parcela de $80 \mathrm{~m}$, esta foi subdividida em 3 subparcelas de $20 \mathrm{~m}$ intercaladas em intervalos, para manobras, de $10 \mathrm{~m}$, sendo determinadas para as quatro posições da barra de tração da grade em cada uma das marchas. A velocidade média de deslocamento do conjunto trator-grade foi avaliada de modo indireto, medido o tempo com auxílio de um cronômetro na subparcela.

Para cada subparcela, na qual se variou a posição da barra de tração e a marcha, foi medida, com o auxílio de uma trena, a largura de corte e a profundidade de corte sendo duas medidas e assim obteve-se a média dos valores.

De posse dos dados obtidos em campo foi realizada a comparação com valores teóricos obtidos nos catálogos dos fabricantes do trator (Valtra) e da grade (Tatu Marchesan) para o cálculo da capacidade de campo teórica (CCT).

Para os cálculos da capacidade de campo efetiva (CCE) utilizou-se a equação 1 conforme Molin e Milan (2002):

$$
C C E=\frac{V^{*} L^{*} e}{10}
$$

Em que:

CCE: capacidade efetiva de campo $\left(\mathrm{ha}^{-1}\right)$;

$\mathrm{V}$ : velocidade de operação $\left(\mathrm{km} \mathrm{h}^{-1}\right)$;

L: largura de trabalho da máquina da maquina $(\mathrm{m})$;

e : eficiência de campo (85\%), segundo Balastreire (2005) varia de 70 a $90 \%$.

Para estimar a força de tração na barra utilizou-se a equação da ASAE (2000) (Equação 2) no momento da operação com grade off-set em preparo primário.

$$
\mathrm{F}=\mathrm{Si} *\left[\mathrm{~A}+\mathrm{B} *(\mathrm{v})+\mathrm{C}^{*}(\mathrm{v})^{2}\right] * \mathrm{~L} * \mathrm{~h}
$$

Em que,

$\mathrm{F}$ : a força requerida para tracionar $(\mathrm{N})$;

$\mathrm{Si}$ : fator adimensional referente à textura do solo;

A B e C: parâmetros específicos de cada grupo de equipamentos, no caso a grade off-set em preparo primário;

$\mathrm{v}$ : velocidade real $\left(\mathrm{km} \mathrm{h}^{-1}\right)$; 
L: largura de trabalho real (m);

h: profundidade de trabalho real $(\mathrm{cm})$.

No modelo ASAE (2000), o parâmetro "A" é função da resistência do solo (364) e os parâmetros "B" $(18,8)$ e "C" $(0,0)$, dependentes da velocidade, são relacionados à densidade do solo. O solo é caracterizado pela textura, sendo "i" igual a 1, 2 ou 3 para solo de textura fina, média ou grossa, respectivamente, sendo, nesse estudo, caracterizado como grossa $(\mathrm{S} 3=0,78)$.

A potência na barra de tração foi determinada de forma indireta pela relação entre força e velocidade para cada tratamento.

Os dados foram analisados por meio da análise de variância e quando os fatores foram significativos a pelo menos $5 \%$ de probabilidade aplicaram-se a regressão polinomial em virtude se tratar de dados quantitativos (PIMENTEL GOMES, 1987). Quando a interação entre os fatores quantitativos foi significativa construiu-se o gráfico com a superfície de resposta.

\section{RESULTADOS E DISCUSSÃO}

Verifica-se pela análise de variância (Tabela 1) da largura de corte o efeito significativo da interação entre a posição da barra de tração e marcha do trator, desse modo construiu-se o gráfico de superfície de resposta considerando os dois fatores. A superfície de resposta da largura de corte (Figura 1) mostra o comportamento decrescente dos valores com o aumento da posição (ângulo de tração), como a maior profundidade de trabalho (Tabela 1). Observa-se que a modificação da posição 1 para a 4 e, consequentemente, dos respectivos ângulos de tração, provocou aumento de exposição da concavidade do disco a linha de tração, de modo que ocorre aumento na capacidade de penetração, assim ocorre aumento da profundidade de trabalho, o que foi verificado pelo trabalho. Mas, para aumentar a capacidade de penetração, tem-se que modificar a exposição do disco a linha de tração, quando isso ocorre há modificação na largura de corte, ou seja, sua diminuição, como verificado no trabalho (Tabela 1 e Figura 1). O efeito das marchas na profundidade de trabalho pode ser verificado pela diminuição da mesma com o aumento da velocidade, devido ao efeito de flutuação ou a menor capacidade de penetração das grades nas maiores velocidades.

TABELA 1. Síntese da análise de variância para a largura de corte e profundidade de trabalho.

(Continua)

\begin{tabular}{lcc}
\hline Fatores & $\begin{array}{c}\text { Largura de corte } \\
(\mathrm{m})\end{array}$ & Profundidade de trabalho $(\mathrm{cm})$ \\
\hline Posição $(\mathrm{P})$ & & $8,9 \mathrm{~B}$ \\
\hline P1 & $2,0 \mathrm{~A}$ & $9,9 \mathrm{~B}$ \\
P2 & $1,9 \mathrm{AB}$ & $10,0 \mathrm{~B}$ \\
P3 & $1,9 \mathrm{AB}$ & $12,9 \mathrm{~A}$ \\
P4 & $1,8 \mathrm{~B}$ & \\
\hline Marchas $(\mathrm{M})$ & & $11,1 \mathrm{~A}$ \\
\hline M1 & $1,9 \mathrm{~A}$ & $10,4 \mathrm{AB}$ \\
M2 & $1,9 \mathrm{~A}$ & $9,8 \mathrm{~B}$ \\
\hline M3 & $1,9 \mathrm{~A}$ & \\
\hline
\end{tabular}

Nucleus, v.9, n.2, out.2012 
TABELA 1. Síntese da análise de variância para a largura de corte e profundidade de trabalho.

(Conclusão)

\begin{tabular}{lcc}
\hline Teste F & \\
\hline $\mathrm{P}$ & $5,33^{*}$ & $23,2^{* *}$ \\
$\mathrm{M}$ & $0,62 \mathrm{~ns}$ & $3,6^{*}$ \\
$\mathrm{P} \times \mathrm{M}$ & $3,41^{* *}$ & $1,23 \mathrm{~ns}$ \\
\hline C.V.P $(\%)$ & 3,6 & 11,7 \\
\hline C.V. M $(\%)$ & 3,5 & 13,4
\end{tabular}

NS: não significativo pelo teste de F. ** Significativo a $1 \%$ de probabilidade pelo Teste $\mathrm{F}$. *Significativo a $5 \%$ pelo Teste F.

FIGURA 1. Superfície de respostada largura de corte $(\mathrm{m})$ para as marchas do trator $\left(\mathrm{km} \mathrm{h}^{-1}\right)$ e posições de abertura das seções da grade leve em tandem com discos de 0,61 m.

$$
\begin{gathered}
\mathrm{L}=2.0309-0.0827 * \mathrm{x}+0.008 * \mathrm{y}+0.0127 * \mathrm{x} * \mathrm{x}-0.0047 * \mathrm{x} * \mathrm{y}-0.0015 * \mathrm{y} * \mathrm{y} \\
\mathrm{R}^{2}=0.90
\end{gathered}
$$

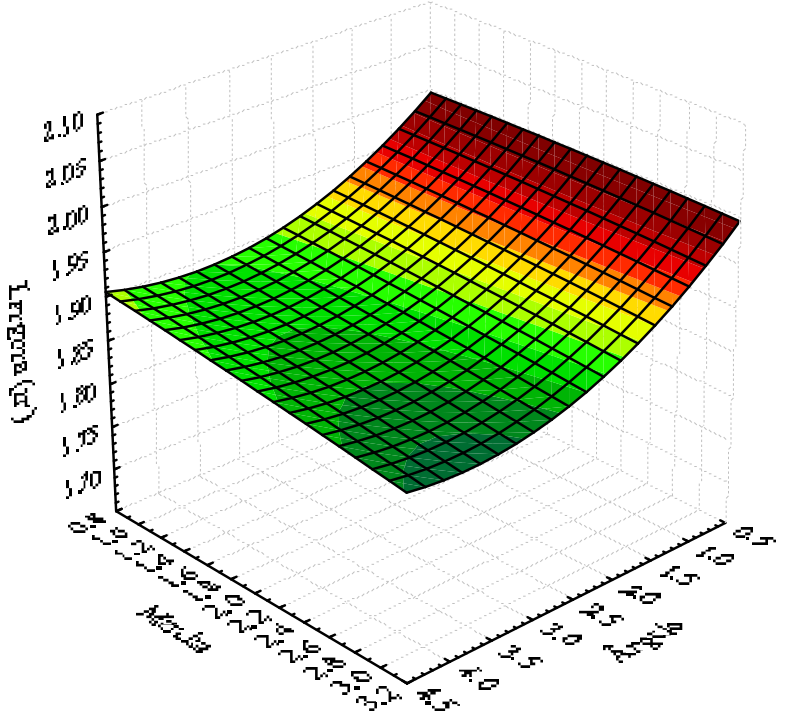

A curva de regressão da profundidade de corte em função da posição da barra de tração e da marcha (Figura 2) apresenta o comportamento crescente com o aumento do ângulo de tração, ou seja, da posição 1 para a posição 4. Desta forma, verifica-se que o deslocamento da barra de tração da grade, para os maiores valores dos ângulos horizontais dos discos da seção dianteira, proporciona uma maior profundidade de trabalho da grade, como encontrado por Silva (2005) e concordando com Stolf (1986), os quais encontraram relação diretamente proporcional entre o aumento do ângulo e da profundidade de trabalho, fato que exige maior força de tração. Verifica-se que nas maiores velocidades ocorreram os menores valores de profundidade de corte, devido provavelmente ao efeito de flutuação da grade (diminuição de profundidade pelo aumento de velocidade). 
FIGURA 2. Análise de regressão polinomial da profundidade de corte para as posições da barra de tração da grade leve em tandem com discos de $0,61 \mathrm{~m}$ e das marchas utilizadas.
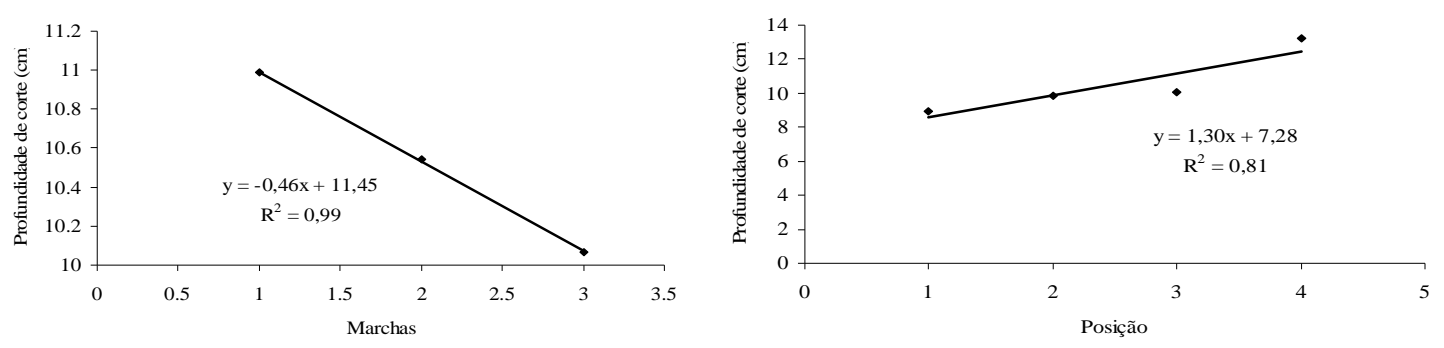

A análise de variância para a velocidade e as capacidades de campo (Tabela 2) mostra o efeito independente dos fatores posições (ângulos) e marchas sobre os mesmos, sendo analisados separadamente por meio da análise de regressão.

TABELA 2. Síntese da análise de variância para a velocidade real de deslocamento e capacidade de campo teórica (CCT) e efetiva (CCE).

\begin{tabular}{lccc}
\hline & $\begin{array}{c}\text { Velocidade } \\
\left(\mathrm{km} \mathrm{h}^{-1}\right)\end{array}$ & $\begin{array}{c}\mathrm{CCT} \\
\left(\mathrm{ha} \mathrm{h}^{-1}\right)\end{array}$ & $\begin{array}{c}\text { CCE } \\
\left(\mathrm{ha} \mathrm{h}^{-1}\right)\end{array}$ \\
\hline Teste F & & & \\
\hline $\mathrm{P}$ & $5,7^{*}$ & $9,4^{* *}$ & $8,5^{* *}$ \\
$\mathrm{M}$ & $26,3^{* *}$ & $24,3^{* *}$ & $25,0^{* *}$ \\
$\mathrm{P} \times \mathrm{M}$ & $0,4 \mathrm{~ns}$ & $0,2 \mathrm{~ns}$ & $0,3 \mathrm{~ns}$ \\
\hline C.V.P $(\%)$ & 15,0 & 14,5 & 14,9 \\
\hline C.V. M $(\%)$ & 14,3 & 13,9 & 14,0 \\
\hline
\end{tabular}

ns: não significativo pelo teste de F. ** Significativo a $1 \%$ de probabilidade pelo Teste F. *Significativo a $5 \%$ pelo Teste F.

A curva de regressão da velocidade real de deslocamento do conjunto trator-grade em função da posição da barra de tração (Figura 3) apresenta os maiores valores nas posições iniciais, com decréscimo suave até as posições finais. Observa-se, portanto, que a maior penetração dos discos no solo em função do aumento da posição (ângulo de tração), influenciou na redução da velocidade de deslocamento do conjunto trator-grade de $10 \mathrm{~km} \mathrm{~h}^{-1}$ (posição 1) até $8 \mathrm{~km} \mathrm{~h}^{-1}$ (posição 4). A curva de regressão da velocidade real de deslocamento do conjunto trator-grade em função da marcha do trator (Figura 3), apresenta os maiores valores de velocidade de deslocamento nas marchas intermediárias e longas (2 e 3, respectivamente), evidenciando que maiores velocidades ocorrem em marchas longas e menores velocidades em marchas curtas, também denominadas de marchas de força.

FIGURA 3. Análise de regressão polinomial da velocidade real de deslocamento do conjunto trator-grade para a posição da barra de tração e as marchas utilizadas.
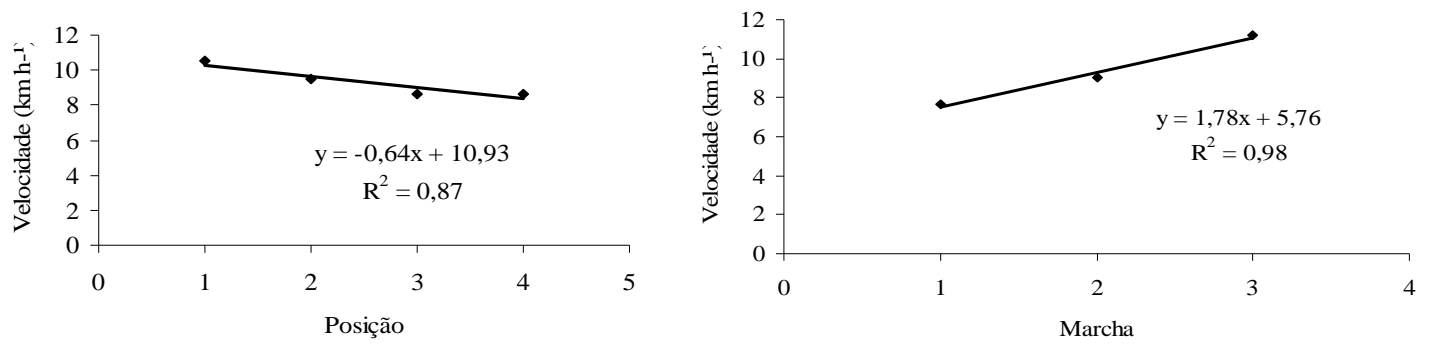
A capacidade de campo teórica em função do ângulo de tração da grade (posição) (Figura 4) apresenta valores maiores nas posições iniciais (1) e finais (4) e, valores menores similares nas posições intermediárias (2 e 3). A capacidade de campo teórica em função da marcha do trator (velocidade) (Figura 4) apresenta os valores crescentes provavelmente devido a influência da velocidade de deslocamento do conjunto que, de forma similar em função da marcha, teve o mesmo comportamento.

FIGURA 4. Análise de regressão polinomial da capacidade de campo teórica do conjunto trator-grade para a posição (ângulo de tração) e as marchas utilizadas (velocidade).
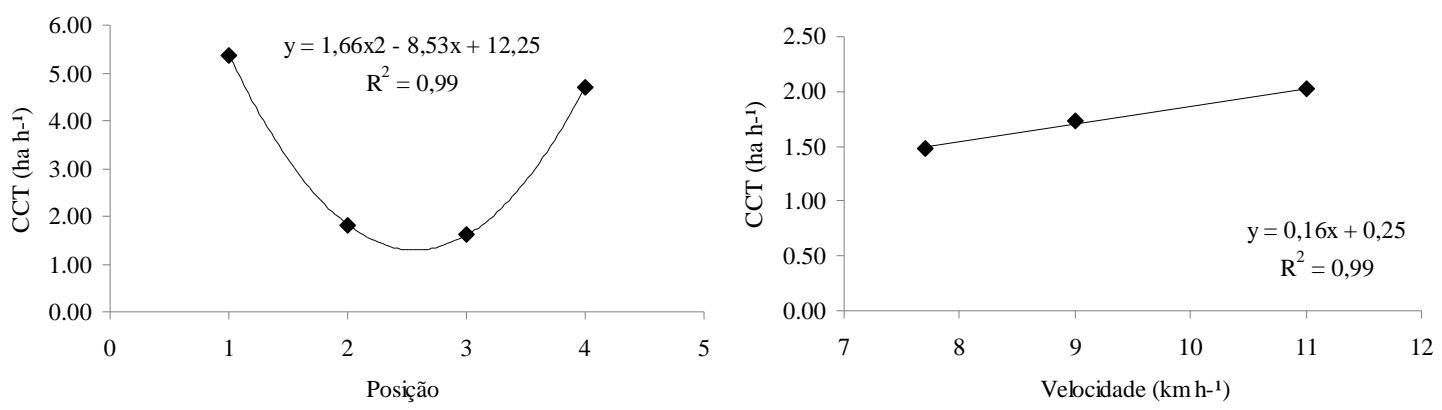

A capacidade de campo efetiva em função do ângulo de tração da grade (Figura 5) apresenta os maiores valores nas posições iniciais, com decréscimo suave até as posições finais. Observa-se que a redução das velocidades de deslocamento do conjunto trator-grade com o aumento da posição do ângulo de tração (Figura 3), influenciou no decréscimo dos valores da capacidade de campo efetiva com o aumento da abertura do ângulo de tração, devido a maior exigência de força, ou seja, da posição 1 para a posição 4. Resultados similares foram encontrados por Tosin et al., (2009); Vitória (2000), quando verificaram que a abertura total da grade proporcionou maiores valores de profundidade de trabalho pelo implemento,o que influenciou no aumento da força de tração, em comparação com a abertura de 50\%.

FIGURA 5. Análise de regressão polinomial da capacidade de campo efetiva do conjunto trator-grade para o ângulo de tração (posições) e as velocidades utilizadas (marchas).
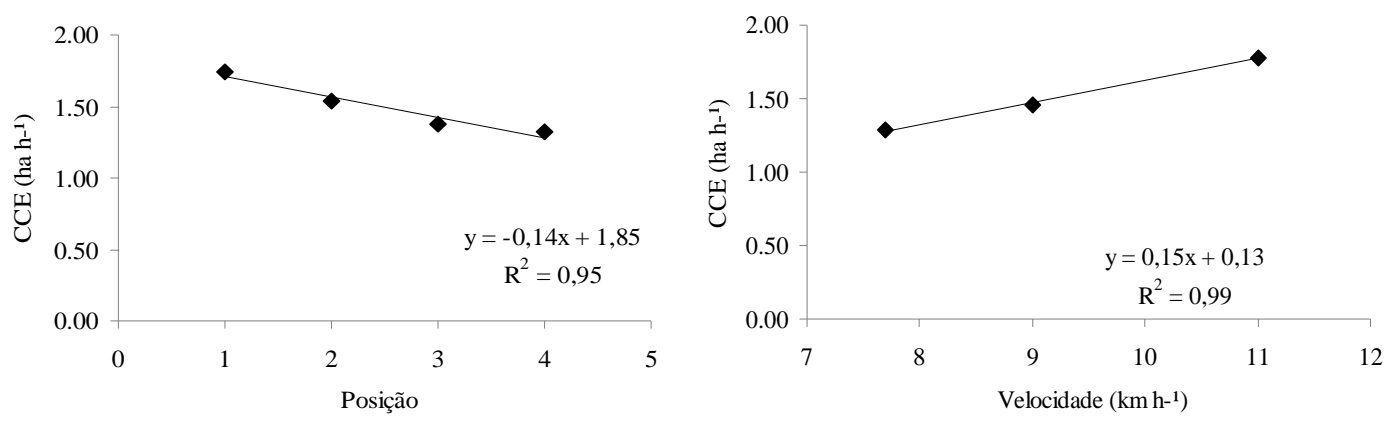

Para a capacidade de campo efetiva em função da velocidade do trator (marchas) (Figura 6) verifica-se que os maiores valores nas marchas mais longas, decresceram de forma suave até as marchas mais curtas. Observa-se que o acréscimo das velocidades de deslocamento do conjunto trator-grade das marchas mais curtas até as mais longas (Figura 3), influenciou no aumento dos valores da capacidade de campo efetiva nas marchas mais longas. Filipovic: Kosutic: Gospodaric (2005) em estudos com arados de 
aivecas verificaram que o aumento na velocidade contribuiu para elevar o consumo de combustível por hora em $10,34 \%$, a capacidade de campo efetiva em $38,89 \%$, e diminuiu a exigência energética por hectare em $20,57 \%$.

Verifica-se que a força de tração e as potências estimadas apresentaram efeitos independentes dos fatores (Tabela 3). Sendo que a força de tração sofreu efeito das posições (ângulos de tração), enquanto que a potência da marcha (velocidade). Fato este verificado para a força de tração que é dependente da profundidade de trabalho que é afetada pelos ângulos, e para a potência que é dependente da velocidade de deslocamento do trator.

TABELA 3. Síntese da análise de variância para a força de tração e potência na barra estimados.

\begin{tabular}{lcc}
\hline & Força de tração $(\mathrm{kN})$ & Potência $(\mathrm{kW})$ \\
\hline Posição (P) & & \\
\hline P1 & $9,8 \mathrm{~B}$ & $28,7 \mathrm{~A}$ \\
P2 & $10,1 \mathrm{~B}$ & $27,1 \mathrm{~A}$ \\
P3 & $9,9 \mathrm{~B}$ & $24,0 \mathrm{~A}$ \\
P4 & $12,7 \mathrm{~A}$ & $29,0 \mathrm{~A}$ \\
\hline Marchas (M) & & $22,7 \mathrm{~B}$ \\
\hline M1 & $10,9 \mathrm{~A}$ & $26,8 \mathrm{AB}$ \\
M2 & $10,6 \mathrm{~A}$ & $32,2 \mathrm{~A}$ \\
M3 & $10,5 \mathrm{~A}$ & \\
\hline Teste F & & $1,95 \mathrm{~ns}$ \\
P & $12,5^{* *}$ & $8,57 * *$ \\
M & $0,2 \mathrm{~ns}$ & $0,26 \mathrm{~ns}$ \\
P x M & $1,2 \mathrm{~ns}$ & 21,1 \\
\hline C.V.P $(\%)$ & 12,5 & 23,8 \\
\hline C.V. M $(\%)$ & 15,1 & S \\
\hline
\end{tabular}

NS: não significativo pelo teste de F. ** Significativo a $1 \%$ de probabilidade pelo Teste F. *Significativo a 5\% pelo Teste F.

A força de tração em função da posição (ângulo de tração) (Figura 6) verifica-se que o comportamento dos valores se assemelha ao crescimento dos valores de profundidade de corte (Figura 2). Observa-se, portanto, aumento da força de tração, das posições 1, 2 e 3 para a posição 4 . Semelhante aos resultados de Stolf (1986) que verificou aumento da força de tração com o aumento do ângulo de abertura, efeito esse, também observado nos estudos de Mello (2004) com arados.

FIGURA 6. Análise de regressão polinomial da força de tração do conjunto trator-grade para a posição (ângulo de tração).

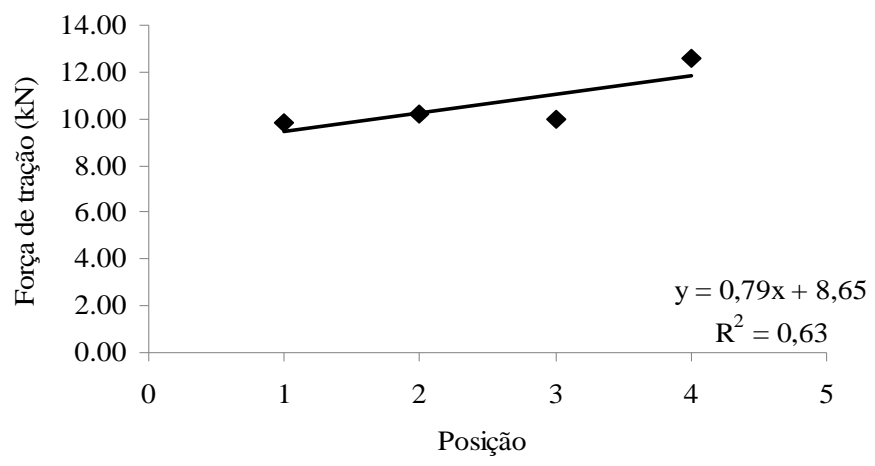


A potência na barra (Figura 7) estimada é influenciada pelas variáveis mensuradas largura, velocidade e profundidade. Verifica-se o efeito da equação de primeiro grau, em que a medida que aumentou a velocidade, ocorreram maiores potências requeridas, quando comparadas com as menores velocidades de deslocamento. Segundo Zoppello et al. (1995), operações em que o trator traciona o arado e a grade de discos, aumenta significativamente a força de tração e a potência.

FIGURA7. Análise de regressão polinomial da potência do conjunto trator-grade para as marchas utilizadas (velocidade).

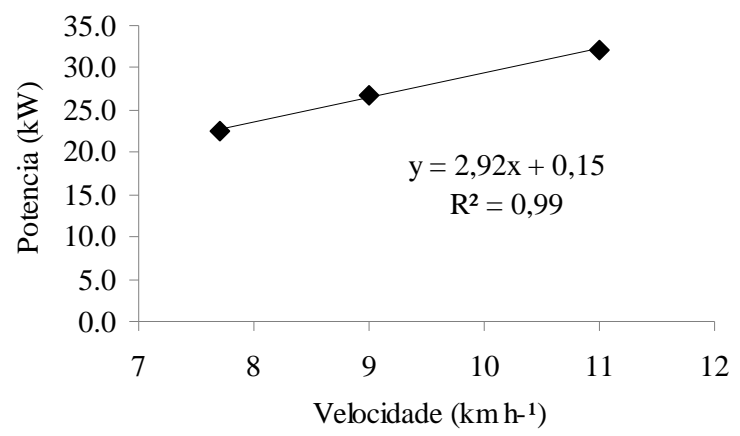

\section{CONCLUSÃO}

Quanto maior a velocidade de deslocamento menor a profundidade de trabalho, e quanto maior o ângulo de tração, maior a profundidade de trabalho, o que indica relação inversa entre velocidade e ângulo de tração para a profundidade de trabalho.

A largura de corte foi maior nos menores ângulos de tração para todas as velocidades de deslocamento.

A velocidade real de deslocamento e a capacidade de campo efetiva diminuem com o aumento do ângulo (posição), devido ao aumento da profundidade de trabalho, e aumenta com a mudança no escalonamento de marcha.

A força de tração e a potência estimada foram afetadas pelo ângulo de tração (posição) e o escalonamento de marchas (velocidade), respectivamente.

\section{REFERÊNCIAS}

ASAE - AMERICAN SOCIETY OF AGRICULTURAL ENGINEERS.ASAE D497.4: agricultural machinery management data. St. Joseph: ASAE, 2000. p.350-357.

BALASTREIRE, L.A. Máquinas Agrícolas. Piracicaba: L.A. Balastreire (Org.), 2007. 307p.

BIANCHINI, A.; SABINO, M.H.C.; BORGES, P.H.M.; SGUAREZZI, J.J. Comportamento operacional de um escarificador de hastes parabólicas em solo de cerrado. Revista Brasileira de Engenharia Agrícola e Ambiental, Campina Grande, v.3, n.3, p. 395-401, 1999.

EMBRAPA. EMPRESA BRASILEIRA DE PESQUISA AGROPECUÁRIA. Sistema Brasileiro de Classificação de Solos. Brasília: Centro Nacional de Pesquisas de Solos, 2006. 370p. 
FILIPOVIC, D.; KOSUTIC, S.; GOSPODARIC, Z. Energy requirement in conventional tillage of silty clay soil in west Slavonia. Journal of Central European Agriculture, v. 05, n.05, p. 383-392, 2005.

MANTOVANI, E.C. Compactação do solo. Informe Agropecuário, Belo Horizonte, v. 13, n. 147, p. 52$5,1987$.

MELLO R C. Alterações físicas em um Latossolo Roxo em função da velocidade de aração e do ângulo horizontal dos discos. Acta Scientiarum. Agronomy, Maringá, v. 26, n. 1, p. 35-40, 2004

MOLIN, J. P.; MILAN, M. Trator-implemento: dimensionamento. Capacidade operacional e custo.In: Gonçalves, J. L. M.; Stape, J. L. (ed.) Conservação e cultivo de solos para plantações florestais. Piracicaba: Instituto de Pesquisas Florestais, 2002. p. 409-436.

PACHECO, E.P. Seleção e custo operacional de máquinas agrícolas.Rio Branco: Embrapa Acre, 2000. 21p. (Embrapa Acre. Documentos, 58).

PIMENTEL GOMES, F. A estatística moderna na agropecuária. Piracicaba: Associação Brasileira para Pesquisa da Potassa e do Fosfato, 1987. 162p.

SILVA, A.P.; LIBARDI, P.L.; CAMARGO, O.A. Influência da compactação nas propriedades físicas de dois Latossolos. Revista Brasileira de Ciência do Solo, Campinas, v. 10, p. 91-95, 1986.

SILVA, L. S. Máquinas e implementos para preparo do solo. Cascavel: editora, 2005. p. 01-17.

STOLF, R. Grades agrícolas: 4- Nova classificação quanto à função no preparo do solo. Alcoolbrás, São Paulo, n. 114, p.69-72. 2007.

STOLF, R. Grades e seus tratores: exemplos práticos de seleção. Álcool \& Açúcar, São Paulo, v.6, n.29, p.62-68, 1986.

TOSIN, R.C.; LANÇAS, K.P.; ARAUJO, J.A.B. Avaliação do ruído no posto de trabalho em dois tratores agrícolas. Energia na Agricultura, Botucatu, v. 24, n.4, p.108-118, 2009.

VITÓRIA, E. L. Avaliação do nível de ruído emitido por tratores em diferentes operações agrícolas. Viçosa: Universidade Federal de Viçosa, 2000. 76p. Dissertação Mestrado.

ZOPPELlO, G.; MONARCA, D.; CECCHINI, M. Aziendeagricole, ilrischio da rumore edilD.Lgs 277/91. Macchine e MotoriAgricoli, Bologna, v.2, n.10, p. 9-16, 1995.

Nucleus, v.9, n.2, out.2012 